Review

\title{
Deployment of Auction Theoretic Models for Spectrum Allocation in Cognitive Radio Networks
}

\author{
Monisha Devi, Nityananda Sarma and Sanjib Kr. Deka \\ Department of Computer Science and Engineering, Tezpur University, Assam-784028, India
}

\author{
Article history \\ Received: 21-03-2020 \\ Revised: 27-04-2020 \\ Accepted: 19-05-2020 \\ Corresponding Author: \\ Monisha Devi \\ Department of Computer \\ Science and Engineering, \\ Tezpur University, Assam- \\ 784028, India \\ Email: mnshdevi@gmail.com
}

\begin{abstract}
Cognitive Radio (CR) is a novel technology which empowers the unlicensed users to opportunistically avail the free channels left unoccupied by the licensed owners. This apparently resolves the spectrum scarcity problem arising in today's telecommunication industry. In this technology, once the free bands (called spectrum holes) are detected using sensing techniques, next there is a need to efficiently redistribute the idle spectrum. Such an allocation process of CR has attracted several researchers across the world to contribute in this domain. With an initiative to analyze the functionality of spectrum allocation, this paper carries out a survey on the allocation mechanisms which have been applied to use the spectrum holes. We primarily focus our exploration on auction theoretic allocation models due to their efficacy in channel allocation. Auction formulation takes the unlicensed users as bidders where they bid for the spectrum holes as the auctioned item. Winner determination strategy and pricing strategy are two important aspects of an auction model which determines a fair allocation pattern and along with decides the monetary benefit of sellers and auctioneer. We go through a detailed study on single-sided auction and double-sided auction which are deployed with different CR network constraints to design the allocation model. Finally, we conclude the paper by underlining some future research directions in this area.
\end{abstract}

Keywords: Cognitive Radio, Dynamic Spectrum Access, Spectrum Allocation, Auction, Spectrum Opportunities

\section{Introduction}

In the past few years, human life got involved with several wireless applications such as smartphones, laptops, personnel digital assistance etc., such that on today's date, life without these appliances seems impossible. Rapid development of these wireless technologies overcrowds the radio spectrum and this consequently results in the spectrum scarcity problem. On the contrary, government organizations follow the static spectrum assignment policy to assign the wireless spectrum to license holders on a long-term basis and for a large geographical area. This enables a licensed user or Primary User (PU) to secure its right over its assigned portion of the radio spectrum so that no other user can access over the assigned spectrum. But, according to the reports from Federal Communications Commission (FCC) (FCC, 2002), large blocks of the licensed spectrum are left unused by the PUs both temporally and spatially. Spectrum occupancy measurements have been performed in different parts of the world to justify the amount of unused spectrum. And as per the reports, spectrum occupancy in Chicago is $17.4 \%$ (McHenry et al., 2006), in New York is $13.1 \%$ (McHenry et al., 2006), in Ireland is $13.6 \%$ (Erpek et al., 2007), in Vietnam is $13.74 \%$ (Nguyen et al., 2011) and in Beijing is $13.5 \%$ (Xue et al., 2013). The figures obtained from the experiments reveal that in all places spectrum utilization is remarkably less, which leads to the wastage of valuable radio frequencies. Hence, these unused portions of the spectrum create the spectrum holes or white spaces. Now, the inefficient use of the spectrum resource demands a new technology which can handle the spectrum opportunities by making them available to the unlicensed users or Secondary Users (SUs). Cognitive Radio (CR) (Akyildiz et al., 2006; Xing et al., 2013) steps forward as a novel adaptive technology which encompasses the dynamic spectrum access techniques (Buddhikot, 2007; Zhao and Sadler, 2007) to opportunistically utilize the white spaces. 


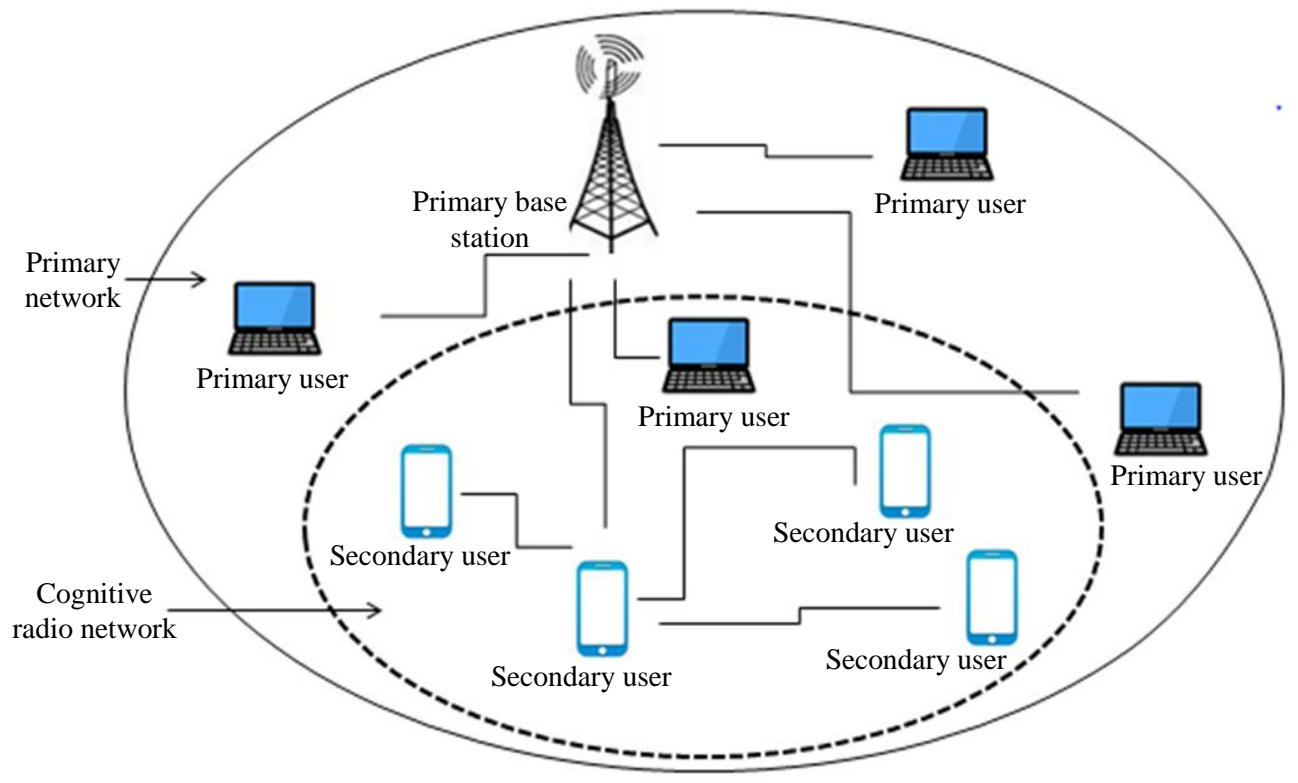

Fig. 1: Cognitive radio network architecture

The concept of Cognitive Radio was introduced by Mitola III and Maguire Jr (1999), who thought of reusing the free radio channels. Being a finite and scarce natural resource, utility patterns of radio spectrum are of utmost importance. CR facilitates a dynamic access to the underutilized spectrum bands. It is a technology which allows the SUs to opportunistically use the spectrum holes without causing any harmful interference to the PUs. Such a network where the unlicensed users are equipped with CR forms a Cognitive Radio Network (CRN). In CRNs, two types of users operate to maximize the public utility (Chen et al., 2008). Primary users are the licensed users having access to an assigned spectrum band. Secondary users are the unlicensed users who can use the CR technology to exploit the free channels temporarily. Figure 1 shows a diagrammatic representation of CRN architecture. To enable strategic use of the vacant spectrum bands, CR implements four main functionalities in its cognitive cycle, viz., spectrum sensing, spectrum management, spectrum sharing and spectrum mobility (Wang and Liu, 2011a; Marinho and Monteiro, 2012; Lu et al., 2012). Spectrum sensing detects the white spaces using different sensing techniques. Also, PU activity is monitored during the sensing phase which can inform the SUs, who are assigned a particular channel, about the return of the PU owing that channel. Then, once the white spaces are identified, the spectrum bands are characterized considering different parameters and the best available frequencies are selected. Thereafter, spectrum sharing distributes the frequency bands amongst different SUs with an aim of improving the spectrum utilization. Once the channels are assigned to the SUs, communication over the channels can be started. But, there can be situations where a PU returns back to reclaim its channel. Then, the SUs operating over that channel immediately vacate the channel and switch to another available channel. This functionality is called spectrum mobility. Therefore, with an incentive to make a fair use of the radio resource, spectrum bands are sensed, characterized and distributed accordingly to provide a seamless communication. Every functionality has its own importance in the cognitive cycle. This paper concentrates on the spectrum sharing functionality of CR where designing of allocation mechanisms to utilize the vacant spectrum is executed.

Once the idle channels are detected by the SUs, allocation approaches are to be applied to share the channels amongst the SUs. Different allocation models are being employed by incorporating different network requirements. Game theory, graph theory, evolutionary theory, auction theory, Markov model and so forth are some of the established allocation models in CRN. Amongst them, application of auction to allocate the channels has been widely accepted amongst the researchers since auction contributes a nondiscriminatory allocation approach. Designing of auction models in a CR network presents a different perspective, where the prime intention of the auction game is to boost the spectrum utilization along with earning of a minimal monetary profit for the sellers. In this paper, we review the state-of-art on the deployment of auction theoretic models for spectrum allocation in CRN. Initially, we present an overview of the spectrum allocation problem which is designed for sharing the available channels. And then, we explore how auction 
becomes advantageous for assigning the channels in a CR environment.

\section{Spectrum Allocation in CRN}

The sensing functionality of CR networks ascertains the spectrum holes so as to spare opportunistic spectrum access among SUs. Thereafter, spectrum sharing (Pandit and Singh, 2015) is responsible for providing a fair allocation of the holes or for designing scheduling protocols which can coordinate channel access amongst the users. In this paper, we carry out a study on the spectrum allocation problem (Xu et al., 2014). This is because, improvement in spectrum utilization largely depends on the channel allocation pattern which is formulated for the deployed network scenario. With spectrum allocation, appropriate frequency bands can be assigned to desired SUs by designing allocation patterns that fulfill certain criteria, while at the same time, retain interference constraints to primary networks. So, designing of allocation mechanisms can become a challenging job, where incorporating the $\mathrm{CR}$ constraints become essential to achieve a good network throughput. The inputs given to an allocation mechanism are the spectrum holes detected by the SUs according to their availability and the output obtained is the allocation pattern planned using the deployed model. Spectrum allocation can be distinguished as power allocation and bandwidth allocation. In power allocation, SUs and the PU can coexist over the same channel. But, for such an approach, it is necessary for the SUs to estimate the interference level that can be tolerated by the PU while sharing the band. Then depending on the tolerable interference, the SUs decide an interference temperature threshold which helps the SUs to adjust their transmission power such that transmission of the PU remains undisturbed. But in bandwidth allocation, the main concern is to make most use of the free channels or to allow maximum number of SUs to get assigned to the available channels. Bandwidth allocation is operated in situations where the available channels are completely free for the SUs. While performing channel assignment, different allocation constraints can be applied, such as, single-channel allocation, multichannel allocation and multi-winner allocation. In single-channel allocation, every SU gets only one channel for its transmission. But, in multi-channel allocation, one SU can be assigned more than one channel, which becomes useful to improve the network throughput. Again, in multi-winner allocation, one common channel can be assigned to multiple SUs at a time, but with the condition that the SUs sharing the channel are non-interfering amongst them. Altogether, spectrum allocation in CRN focuses on dynamic allocation of the free channels constrained to different network conditions and proposes approaches that look for exploiting some of the established allocation models (Ahmed et al., 2016; Tragos et al., 2013). One such kind of spectrum allocation model that perceives the sharing process amongst SUs is the auction theoretic model wherein PUs desire to lease their unused channels to the SUs in convenient prices. In the next section, we provide a detailed discussion on auction in CRN.

\section{Auction for Spectrum Allocation in CRN}

In this section we carry out a preliminary study on different auction types and then, we discuss how auction is being deployed in CRN as an allocation model.

\section{Auction: An Overview}

Auction (Krishna, 2002; Parsons et al., 2011) provides a well-endowed platform for solving problems related to allocation of resources with an incentive to impart an acceptable allocation pattern among bidders. Main components that build up an auction model are: bidders (buyers), who submit bids to gain access to a resource; sellers, who intend to sell the item kept for lease in turn of some monetary profit; auctioned item, which is to be auctioned amongst the bidders; and the auctioneer, who presides over the entire auction process to come up with an effective decision. Bidders submit bid values whereas sellers submit ask values on auctioning an item. Each bid/ask renders information that signifies the buyer's/seller's preferences, requirements or requests for the commodity to be traded and the outcome for the auction is conditioned solely on the basis of the received bids from buyers. Moreover, an auction game gets characterized by two salient features, viz. winner determination strategy and pricing strategy. Auction appears as a good choice that seeks to determine values for items with unknown prices and allows the most effectual bidder to win the game. Players participating in an auction compete amongst them to get hold of the auctioned item. Existing auctions can be classified into several types based on different criteria, as summarized in Table 1 (Krishna, 2002; Parsons et al., 2011).

Designing auctions need strategic bidding policies so as to achieve a proper allocation pattern. An auction format gets assessed according to either of the two attributes, viz., efficiency, allocating items to those who value them the most, or revenue, total of the pricing cost. Valuation for an item accounts to an amount above which bidders do not submit their bids so as to earn a positive benefit. As an ideal solution, bidding the true valuation puts forward a dominant strategy for several auction frameworks wherein no bidder thinks of deviating unilaterally from its bidding strategy. Some of the existing auction models that are operated upon are summarized in Table 2 (Krishna, 2002; Parsons et al., 2011). 
Table 1: Common auction types categorized based on different criteria

\begin{tabular}{|c|c|c|}
\hline Criteria & Auction type & Feature \\
\hline \multirow[t]{2}{*}{ Behavior of bids } & Open cry auction & Bids from buyers are publicly made available \\
\hline & Sealed bid auction & Bids are submitted in sealed envelope which is only known to the auctioneer \\
\hline \multirow[t]{2}{*}{ Number of units } & Single-unit auction & Only one unit is offered by a seller for bidding \\
\hline & Multi-unit auction & Multiple units are put forward such that a bidder can bid for many items \\
\hline \multirow[t]{2}{*}{ Bidding behavior } & Forward auction & Bidders submit bids in order to gain access to the auctioned resource \\
\hline & Reverse auction & $\begin{array}{l}\text { Sellers submit asks that amount to the values that they are willing to earn on leasing } \\
\text { their resource }\end{array}$ \\
\hline \multirow[t]{2}{*}{ Bidding direction } & Single-sided auction & Either bidders submit their bids or sellers submit their asks for the auction \\
\hline & Double-sided auction & $\begin{array}{l}\text { Both bidders and sellers submit their bids and asks respectively which introduces } \\
\text { competition amongst bidders and sellers separately }\end{array}$ \\
\hline \multirow[t]{2}{*}{ Behavior of players } & Static auction & Players do not revise their bidding strategies \\
\hline & Dynamic auction & Players can update their designed policies on receiving information from other players \\
\hline
\end{tabular}

Table 2: Common auction models in literature

\begin{tabular}{|c|c|c|}
\hline Auction model & Operation & Characteristics \\
\hline English auction & $\begin{array}{l}\text { Auctioneer discloses a low price among bidders which is then } \\
\text { increased progressively till a single bidder remains who is } \\
\text { declared as winner of the game and is charged the final price. }\end{array}$ & $\begin{array}{l}\text { Open-cry, ascending } \\
\text { bid, dynamic }\end{array}$ \\
\hline Dutch auction & $\begin{array}{l}\text { Seller announces a high reserve price among bidders which is } \\
\text { then gradually dropped until some bidder agrees over the standing } \\
\text { price to win the item at the last declared price. }\end{array}$ & $\begin{array}{l}\text { Open-cry, descending } \\
\text { bid, dynamic }\end{array}$ \\
\hline $\begin{array}{l}\text { Sealed-bid first } \\
\text { price auction }\end{array}$ & $\begin{array}{l}\text { Bids from bidders are in sealed form with no knowledge of bids } \\
\text { to others. Bidder who offers highest bid wins the game and is } \\
\text { charged to pay his bid. }\end{array}$ & $\begin{array}{l}\text { Sealed-bid, static, } \\
\text { truthful }\end{array}$ \\
\hline $\begin{array}{l}\text { Sealed-bid second } \\
\text { price (Vickrey) auction }\end{array}$ & $\begin{array}{l}\text { Bids from bidders are in sealed form with no knowledge of bids } \\
\text { to others. Bidder who offers highest bid wins the game and is } \\
\text { charged to pay the second highest bid value. }\end{array}$ & $\begin{array}{l}\text { Sealed-bid, static, } \\
\text { single-unit, truthful }\end{array}$ \\
\hline $\begin{array}{l}\text { Vickrey Clarke } \\
\text { Groves (VCG) auction }\end{array}$ & $\begin{array}{l}\text { Generalized form of Vickrey auction that allows auctioning of } \\
\text { multiple items. }\end{array}$ & $\begin{array}{l}\text { Sealed-bid, multiunit, } \\
\text { truthful }\end{array}$ \\
\hline $\begin{array}{l}\text { Simultaneous } \\
\text { ascending auction }\end{array}$ & $\begin{array}{l}\text { Multiple items are auctioned simultaneously wherein bidders can } \\
\text { submit bids for many items. }\end{array}$ & Sealed-bid, multiunit \\
\hline
\end{tabular}

\section{Auction for Spectrum Allocation in CRN}

The use of spectrum auction started long back in 1993 by US Congress (Chattopadhyay, 2014) and within a short time, this method got spread across most countries of the world. On today's date, auction plays an important role for the telecommunication regulatory bodies because applying auction to distribute the licensed spectrum helps them to generate sufficient revenue. Moreover, due to the open and transparent behavior of an auction model, it is also considered as one of the widely used allocation model in CRN. In order to make adequate use of the spectrum resource, dynamic spectrum allocation using auction has become a promising approach that allows SUs to acquire unused licensed bands leased by the sellers. Studies referring to auction-based spectrum allocation in CRN take up multi-unit auction type for permitting access to multiple units of the available spectrum. Bidders pursue a non-cooperative behavior amongst themselves so as to acquire their preferred choices. In an auction framework, SUs, participating as bidders, determine their requisite measurements considering different spectrum characteristics and accordingly submit bids to the auctioneer with an incentive to obtain proper spectrum access. Available spectrum gets allocated by deploying winner determination strategy that allows the bidders, who are most deserving, to win the game so that the auctioned items move to the bidders who value them the most, thus, optimizing the system efficiency. Sequentially, pricing strategies allow the auctioneer and sellers to earn revenue for their leased goods. Altogether, auction provides a platform where the radio spectrum gets assigned among users with improved utilization.

Auction models designed for CR network are either single-sided or double-sided. And accordingly, auction components vary in both the auction types. In a singlesided auction, only bids are submitted to the auctioneer, there is no participation of the sellers to earn any monetary profit. SUs act as bidders and the primary owner (base station of the primary network) acts as the 
auctioneer. Primary Owner (PO) determines the winning bidders to lease the channels which are left unused by the PUs and along with obtains a revenue for carrying out the allocation process. Whereas, in a double-sided auction, both bids and asks are submitted to the auctioneer. That is, both bidders and sellers compete amongst themselves to increase their own profit. In a double-sided auction, SUs act as bidders, POs act as sellers and the Spectrum Broker (SB) in the network acts as the auctioneer. Different POs offer ask values to sell their respective channels which are kept free by the PUs and also plan to earn a profit from the sold channels. The auctioneer decides the clearing price to determine the winning bidders and sellers and obtains a revenue which is the difference between the payment paid by the bidders and price offered to the sellers. In CRN, the prime objective is to improve the spectrum utilization, so the designed auction model mainly focuses on system efficiency. Most of the auction models maintain a reserve price which is set by the auctioneer so that at least a minimal payment can be acquired by the auctioneer. To decide the winners in the auction, winner determination strategy is developed which gives the allocation pattern. Also, every winning bidder has to pay a price to the auctioneer and every winning seller obtains a payment from the auctioneer. For both the payments, a payment strategy is developed such that it satisfies the economic properties for truthfulness and individual rationality. Every winning bidder or seller computes a utility which counts to be the difference between valuation and payment. So, to design a truthful auction, no bidder or seller should be able to improve its utility by submitting an untruthful bid (a bid is truthful if bid value is equal to the valuation). Also, for individual rationality, every bidder or seller should be able to obtain a non-negative utility. Hence, the auction model designed in a CR environment must be economically robust to achieve an efficient allocation.

Auction proffers a paradigm for allocating spectrum resources in a non-cooperative manner by following a sealed-bid auction. As such, a reduced communication overhead is offered by auction theoretic models, wherein the bidders and the sellers submit bids and asks only to auctioneer. No bidder/seller realizes the bidding strategies of any other bidder/seller. This facilitates no interaction between bidders/sellers themselves. They communicate only with the auctioneer. Auction puts forward a more practical approach since the PUs themselves are willing to lease the channels while proceeding for spectrum allocation decisions. Further, auction-based methods commit every participant an equal opportunity to win the game and the bidders with higher bids retain a greater chance to obtain their preferred item. Auction scenarios settle the prices through a bidding procedure without having any prior information on spectrum price. Therefore, deploying auction models can be a good choice for accomplishing spectrum allocation performance in CRN. Figure 2 shows a flowchart which describes how auction is formulated in CRN. Both single-sided and double-sided auctions are represented in the figure. In today's communication world which is moving towards 5G technology (Hu et al., 2018; Hindia et al., 2020), CR can play an important role. To achieve higher capacity in $5 \mathrm{G}$ network, CR can be incorporated to provide flexibility in spectrum availability. Moreover, deployment of auction models for spectrum allocation can be advantageous since the PUs themselves give away their free channels for a certain time period. Also, security can be preserved in the network since the network operators may not want to communicate amongst themselves and using of auction can be favorable because communication takes place only with the auctioneer. Other applications of CRN are in public safety networks, smart grid networks, wireless medical networks etc. (Wang et al., 2011a).

\section{Literature Survey on Auction Models in CRN}

Researchers have already developed several auctionbased spectrum allocation mechanisms for CRN which are either single-sided or double-sided. We separately explore the two auction types.

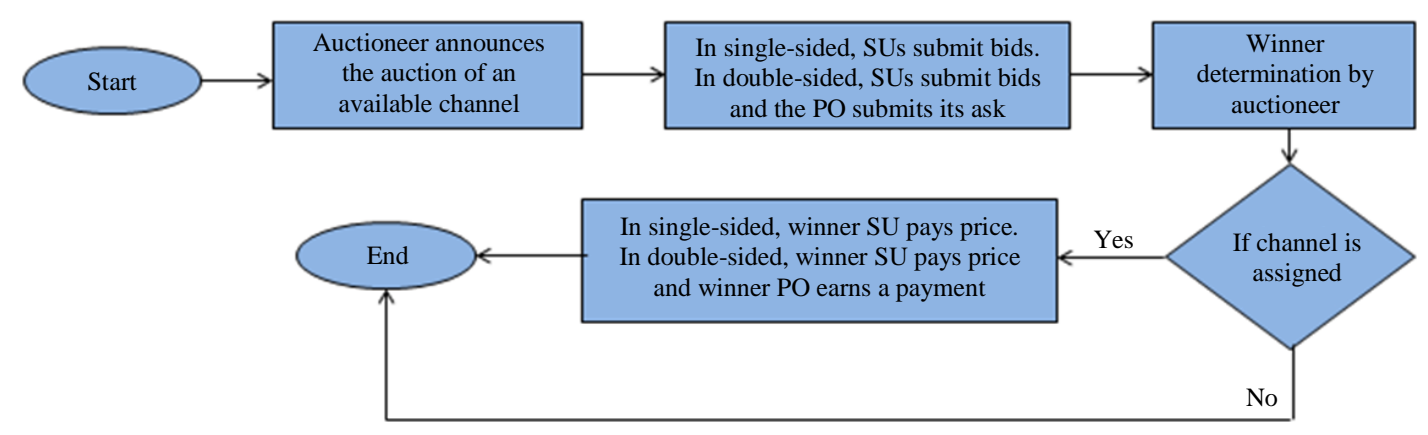

Fig. 2: Flowchart showing single-sided and double-sided auctions in CRN 
In single-sided auction, participation is only from the bidder's side. Such an auction model is designed in (Wang et al., 2010a) where the bidders request for bandwidth from the auctioneer. A dynamic updating algorithm plans the allocation for both single-PU and multiple-PU scenarios. A strategy proof auction mechanism has been developed in (Kash et al., 2014) which allows sharing of spectrum by both sharers and exclusive-use bidders. A conflict graph models the interference between the users and bucketing and ironing techniques are deployed to obtain the allocation. Authors in (Khaledi and Abouzeid, 2013) formulated a singlechannel allocation based auction model which uses a bipartite graph to represent the SUs and the channels. To determine a winning SU for every available channel, a maximal weight matching algorithm is implemented in the bipartite graph. And for the payment, VCG auction is applied to determine the price paid by every winning SU to the auctioneer. Another single-sided auction model which uses the first price auction and English auction is developed in (Amraoui et al., 2012). On using the first price auction, the bidder with the highest bid is picked as the winner and the payment paid is the winning bid value. But, in English auction, multiple rounds are carried out till a single bidder remains who satisfies with the incremented bid value and pays the final declared bid. A revenue maximization problem is formulated as an auction model in (Gao et al., 2011) where to characterize the channels, the authors use the channel capacity as the quality of a channel. And then to bid for the channels, a quality-price combination is considered which are collected at the auctioneer to decide a feasible solution for channel allocation. Another auction model for revenue generation is proposed in (Jia et al., 2009) where an optimal auction is designed using the concept of virtual valuation. Then to reduce the computational complexity, authors propose a sub-optimal solution for the problem with monotone allocation. A sequential bidding based auction model is developed in (Devi et al., 2017) where single-unit-single-user allocation is performed but in such a way that no two adjacent channels get assigned to interfering SUs. This helps to prevent adjacent channel interference in the network while allowing the SUs to dynamically use the spectrum holes. Again, a multi-winner auction model has been proposed in (Devi et al., 2020a) where non-interfering SUs can be assigned a common channel. The bids for the heterogeneous channels are taken in terms of data rate which provides a better use of the radio spectrum. In (Sengupta and Chatterjee, 2008), both sequential and concurrent bidding strategies are applied separately to the auction mechanism for dynamic spectrum allocation. Revenue generation and determining the optimal bid value are considered for performance analysis, where the authors designed the auction mechanism based on the knapsack problem. Apart from bandwidth allocation, power allocation also applies single-sided auction as in (Huang et al., 2006), where users are charged for their received SINR and power.

In double-sided auction, participation is both from the bidder's side and the seller's side. McAfee auction (McAfee, 1992) is the general double auction model which allows single-unit allocation with single-winner. Bids and asks are sorted in descending order and ascending order respectively and then an index is decided which chooses the winning sellers and buyers in McAfee. TRUST is a double-auction model proposed in (Zhou and Zheng, 2009) which extends the general McAfee auction to design the allocation pattern with spectrum reuse. But in TRUST, every seller can sell only a single channel and one SU can acquire only one channel. A double-auction with multi-channel allocation has been developed in (Chen et al., 2013) where spectrum reuse is handled using virtual buyer group formation algorithm. Bid for each group is decided based on two bidding policies and McAfee auction finds the winners for both sellers and buyers. SMALL (Wu and Vaidya, 2011) has been proposed as another double auction model which supports multi-channel allocation. Conflict graph formation models the interfering SUs which then allows a channel to be assigned to multiple non-interfering SUs at a time. Dong et al. (2016), authors decoupled both the buyer side and the seller side and winner determination is performed separately. In the buyer side, SUs are modeled using a graph and graph partitioning is carried out to form the subgraphs which are also used to determine the payments of SUs. In the seller side, every seller auctions a single channel using traditional auction methods. STRUCTURE in (Sun et al., 2015) has been designed as another single-channel allocation based auction model where bid-dependent buyer groups are formed to enable multi-winner allocation. Channels auctioned by the sellers are heterogeneous in terms of channel frequencies and this accordingly decides the ask values. In (Khairullah and Chatterjee, 2019), a doubleauction for heterogeneous channels has been introduced which is named as PreDA. Based on the SINR values, a preference list is formed for the available channels and bids from SUs get submitted according to the preference list. To enable spectrum reuse, virtual groups are formed among the bidders. Also multi-channel allocation has been applied to facilitate the network throughput. Again, authors in (Devi et al., 2020b) designed DAMW where for multi-winner allocation, a group formation algorithm is implemented which forms groups of non-interfering SUs. A group bid is computed for each group considering CR network constraints and then channel allocation proceeds with the group bids and the ask values. A double auction which optimizes the profit earned along with low energy consumption is proposed in (Zhai et al., 2018). Another double auction model DOTA in (Wang et al., 2012) designs the auction for 
both range request and strict request. In range request, demand of an SU can be partially satisfied or fully satisfied. But in strict request, the demand of an SU needs to be fully satisfied for deciding the winning sellers and buyers. Spectrum reuse and multi-channel allocation are incorporated in DOTA to improve the spectrum utilization. TAMES is a multi-seller-multibuyer double auction (Chen et al., 2014) which is developed with spatial reuse characteristic. Since the channels for auction are heterogeneous in their quality, so a heterogeneous interference graph is designed to group the non-conflicting SUs using sequential grouping. In (Liu and $\mathrm{Li}, 2017$ ), authors propose a predictive double auction methodology where the bidding ranges are computed using a Markovian prediction algorithm. Spectrum reuse is enabled in the model to improve the spectrum utilization and all the economic properties are satisfied to provide economic robustness. A local market based auction model is designed in (Wang et al., 2011b) where the licensed user has the right to partition its license area and carry out the auction separately in each area. Here, an extension of the TRUST mechanism is applied in every cell to get the channel allocation and price values. Again in ( $\mathrm{Su}$ et al., 2011), a bilateral multi-unit auction distributes the channels of different heterogeneous networks. A bidindependent grouping algorithm forms groups of noninterfering users for spectrum reuse and the winner determination algorithm decides the allocation strategy amongst bidders. LOTUS (Chen et al., 2015) is an online double auction model which uses location heterogeneity to improve the spectrum utility. Based on the location of the bidders, an interference graph is constructed so that spectrum reusability can be facilitated. The concept of interference discount used in (Chen et al., 2015) decides the bid value of a bidder, so that the allocation process carried out using the bids can provide an allocation which reduces harmful interference amongst the buyers. Another online double auction is named as TODA (Wang et al., 2010b) which follows strategy proof auction mechanism and uses a complete conflict graph to allow channel reuse. Double-sided auction also becomes favourable for power allocation. Zhang et al. (2018), both the PU and the SUs are allowed to share a common channel while maintaining the interference level from the SUs. A threshold level for the interference temperature is maintained which primarily helps to prevent the interference. Another spectrum trading double auction is proposed in (Teng et al., 2011) which aims at achieving a fair spectrum access among SUs and PUs. Two different utility functions are used to show the preferences in bidding decisions and then to manage the spectrum, authors apply the supply and demand relationship.

Hence, the above literature study discusses some of the auction models deployed for CRN with different allocation conditions which aim at improving the spectrum use. Table 3 shows a comparison of some of the existing auction models used in CRN.

Table 3: Auction mechanisms for CRN

\begin{tabular}{|c|c|c|c|c|c|c|}
\hline Reference & $\begin{array}{l}\text { Single-sided } \\
\text { auction }\end{array}$ & $\begin{array}{l}\text { Double-sided } \\
\text { auction }\end{array}$ & Single-winner & Multi-winner & $\begin{array}{l}\text { Single-channel } \\
\text { allocation }\end{array}$ & $\begin{array}{l}\text { Multi-channel } \\
\text { allocation }\end{array}$ \\
\hline Wang et al. (2010a) & $\checkmark$ & $x$ & $\checkmark$ & $x$ & $\checkmark$ & $x$ \\
\hline Kash et al. (2014) & $\checkmark$ & $x$ & $\checkmark$ & $x$ & $\checkmark$ & $x$ \\
\hline Khaledi and Abouzeid (2013) & $\checkmark$ & $x$ & $\checkmark$ & $x$ & $\checkmark$ & $x$ \\
\hline Amraoui et al. (2012) & $\checkmark$ & $x$ & $x$ & $\checkmark$ & $\checkmark$ & $x$ \\
\hline Gao et al. (2011) & $\checkmark$ & $x$ & $x$ & $\checkmark$ & $\checkmark$ & $x$ \\
\hline Jia et al. (2009) & $\checkmark$ & $\times$ & $x$ & $\checkmark$ & $\checkmark$ & $x$ \\
\hline Devi et al. (2017) & $\checkmark$ & $x$ & $\checkmark$ & $\times$ & $\checkmark$ & $x$ \\
\hline Devi et al. (2020a) & $\checkmark$ & $x$ & $x$ & $\checkmark$ & $\checkmark$ & $x$ \\
\hline McAfee (1992) & $\times$ & $\checkmark$ & $\checkmark$ & $x$ & $\checkmark$ & $x$ \\
\hline Zhou and Zheng (2009) & $x$ & $\checkmark$ & $x$ & $\checkmark$ & $\checkmark$ & $x$ \\
\hline Chen et al. (2013) & $x$ & $\checkmark$ & $x$ & $\checkmark$ & $x$ & $\checkmark$ \\
\hline Wu and Vaidya (2011) & $\times$ & $\checkmark$ & $x$ & $\checkmark$ & $x$ & $\checkmark$ \\
\hline Dong et al. (2016) & $\times$ & $\checkmark$ & $x$ & $\checkmark$ & $\checkmark$ & $x$ \\
\hline Zhang et al. (2018) & $x$ & $\checkmark$ & $x$ & $\checkmark$ & $\checkmark$ & $x$ \\
\hline Sun et al. (2015) & $x$ & $\checkmark$ & $x$ & $\checkmark$ & $\checkmark$ & $x$ \\
\hline $\begin{array}{l}\text { Khairullah and } \\
\text { Chatterjee (2019) }\end{array}$ & $x$ & $\checkmark$ & $x$ & $\checkmark$ & $\times$ & $\checkmark$ \\
\hline Devi et al. (2020b) & $\times$ & $\checkmark$ & $x$ & $\checkmark$ & $\checkmark$ & $x$ \\
\hline Zhai et al. (2018) & $x$ & $\checkmark$ & $x$ & $\checkmark$ & $\checkmark$ & $x$ \\
\hline Wang et al. (2012) & $\times$ & $\checkmark$ & $x$ & $\checkmark$ & $x$ & $\checkmark$ \\
\hline Chen et al. (2014) & $\times$ & $\checkmark$ & $x$ & $\checkmark$ & $x$ & $\checkmark$ \\
\hline Wang et al. (2011a) & $\times$ & $\checkmark$ & $x$ & $\checkmark$ & $x$ & $\checkmark$ \\
\hline
\end{tabular}




\section{Future Research Directions}

CRN plays a key role in solving the spectrum scarcity problem. Amongst different functionalities in CR, spectrum sharing is one such functionality which helps to fairly distribute the free channels. And to facilitate the sharing process, use of auction provides an effective solution. However, there are certain constraints in a CR network which when integrated in the auction model significantly affect the auction process. In CRN, all the channels left free by the PUs may not be available to every SU. That is, the set of channels sensed by one SU may be different with the set that is sensed by another SU. This arises due several hardware constraints faced by the SUs during the spectrum sensing process which results in different SU capabilities. As such, if an SU wins a channel which is actually unavailable at the SU, then this affects the network throughput and degrades the performance. Also, due to the return of a PU to its owned channel, the transmission of the SU who has been using the channel can get disturbed. So, to overcome such a situation, every SU should be aware of the availability time of its sensed channels and accordingly bid for a channel only when the channel availability time is more than the time for which the SU requires the channel. This also helps to reduce the switching overhead in CRN. Hence, incorporating such network constraints can improve the overall spectrum utility and network performance.

\section{Conclusion}

Spectrum allocation is one of the key functionalities of CRN where the free channels from PUs can be efficiently shared amongst the SUs. Different allocation models have been formulated to solve the channel allocation problem. This paper reviews the auction-based approaches where SUs bid for their available channels. Different types of auction can be taken up in different network scenarios to render a fair allocation of the spectrum bands. Auction models can be advantageous from several aspects which have been pointed out while discussing the application of auction in CRN. Also, in this paper, we come up with some of the research challenges which when incorporated with the auction models can significantly improve the spectrum utilization as well as network performance.

\section{Authors Contributions}

Monisha Devi: Carried out the study on the domain, organizing the paper contents and drafting the paper.

Nityananda Sarma: Final reviewing of the paper to get the final draft.

Sanjib Kr. Deka: Organizing the contents in the paper and reviewing it.

\section{Ethics}

This paper is original and contains unpublished material. The authors confirm that there is no conflict of interest involved.

\section{References}

Ahmed, E., A. Gani, S. Abolfazli, L.J. Yao and S.U. Khan, 2016. Channel assignment algorithms in cognitive radio networks: Taxonomy, open issues and challenges. IEEE Commun. Surveys Tutorials, 18: 795-823. DOI: 10.1109/COMST.2014.2363082

Akyildiz, I.F., W.Y. Lee, M.C. Vuran and S. Mohanty, 2006. Next generation/dynamic spectrum access cognitive radio wireless networks: A survey. Comput. Netw., 50: 2127-2159.

DOI: 10.1016/j.comnet.2006.05.001

Amraoui, A., B. Benmammar, F. Krief and F.T. Bendimerad, 2012. Auction-based agent negotiation in cognitive radio ad hoc networks. Proceedings of the 4th International Conference on Ad Hoc Networks, (AHN' 12), Springer, Paris, France, pp: 119-134. DOI: 10.1007/978-3-642-36958-2_9

Buddhikot, M.M., 2007. Understanding dynamic spectrum access: Models, taxonomy and challenges. Proceedings of 2nd IEEE International Symposium on New Frontiers in Dynamic Spectrum Access Networks, Apr. 17-20, IEEE Xplore Press, Dublin. DOI: $10.1109 /$ DYSPAN.2007.88

Chattopadhyay, S., 2014. Telecom spectrum auctions in India: The theory and the practice. Working Paper Series, WPS No. 741.

Chen, Z., H. Huang and L. Huang, 2013. True-MCSA: A framework for truthful double multi-channel spectrum auctions. IEEE Trans. Wireless Commun., 12: 3838-3850.

DOI: 10.1109/TWC.2013.071113.121172

Chen, Y., P. Lin and Q. Zhang, 2015. LOTUS: Location aware online truthful double auction for dynamic spectrum access. IEEE Trans. Wireless Commun., 14: 1092-1099. DOI: 10.1109/TWC.2014.2364266

Chen, K., Y. Peng, N. Prasad, Y. Liang and S. Sun, 2008. Cognitive radio network architecture: Part I general structure. Proceedings of the 2nd International Conference on Ubiquitous Information Management and Communication, Jan. 31-Feb. 1, ACM, Suwon, Korea, pp. 114-119.

DOI: $10.1145 / 1352793.1352817$

Chen, Y., J. Zhang, K. Wu and Q. Zhang, 2014. TAMES: A truthful double auction for multidemand heterogeneous spectrums. IEEE Trans. Parallel Distributed Syst., 25: 3012-3024.

DOI: 10.1109/TPDS.2013.294 
Devi, M., N. Sarma and S.K. Deka, 2020a. Multi-winner heterogeneous spectrum auction mechanism for channel allocation in cognitive radio networks. Proceedings of the International Conference on Distributed Computing and Internet Technology, Jan. 9-12, Springer India, pp: 251-265.

DOI: 10.1007/978-3-030-36987-316

Devi, M., N. Sarma and S.K. Deka, 2020b. DAMW: Double auction multi-winner framework for spectrum allocation in cognitive radio networks. Proceedings of the 20th International Conference on Innovations for Community Services, Jan 12-14, Springer, India, pp: 266-281.

DOI: 10.1007/978-3-030-37484-615

Devi, M., N. Sarma, S.K. Deka and P. Chauhan, 2017. Sequential bidding auction mechanism for spectrum sharing in cognitive radio networks. Proceedings of the IEEE International Conference on Advanced Networks and Telecommunications Systems, Dec 17-20, IEEE Xplore Press, India.

DOI: 10.1109/ANTS.2017.8384188

Dong, W., S. Rallapalli, L. Qiu, K.K. Ramakrishnan and Y. Zhang, 2016. Double auctions for dynamic spectrum allocation. IEEE/ACM Trans. Network., 24: 2485-2497.

DOI: 10.11091109/TNET.2015.2476497

Erpek, T., K. Steadman and D. Jones, 2007. Dublin Ireland spectrum occupancy measurements. Shared Spectrum Company.

FCC, 2002. FCC Document ET Docket No. Spectrum Policy Task Force Report, Federal Communications Commission.

Gao, L., X. Wang, Y. Xu and Q. Zhang, 2011. Spectrum trading in cognitive radio networks: A contract theoretic modeling approach. IEEE J. Selected Areas Commun., 29: 843-855.

DOI: $10.1109 /$ JSAC.2011.110415

Hindia, M.N., F. Qamar, H. Ojukwu, K. Dimyati and A.M. A-Samman et al., 2020. On platform to enable the cognitive radio over $5 \mathrm{G}$ networks. Wireless Personal Commun.

DOI: 10.1007/s11277-020-07277-3

Huang, J., R.A. Berry and M.L. Honig, 2006. Auctionbased spectrum sharing. Mobile Netw. Applic., 11: 405-408.

Hu, F., B. Chen, K. Zhu, 2018. Full spectrum sharing in cognitive radio networks toward 5G: Asurvey. IEEE Access, 6: 15754-15776.

DOI: $10.1109 /$ ACCESS.2018.2802450

Jia, J., Q. Zhang, Q. Zhang and M. Liu, 2009. Revenue generation for truthful spectrum auction in dynamic spectrum access. Proceedings of the ACM International Symposium on Mobile Ad hoc Networking and Computing, May 18-20, ACM, USA, pp: 3-12. DOI: 10.1145/1530748.1530751
Kash, I.A., R. Murthy and D.C. Parkes, 2014. Enabling spectrum sharing in secondary market auctions. IEEE Trans. Mobile Comput., 13: 556-568. DOI: $10.1109 /$ TMC.2013.17

Khairullah, E.F. and M. Chatterjee, 2019. PreDA: Preference-based double auction for spectrum allocation in heterogeneous DSA networks. Comput. Commun., 133: 41-50.

DOI: $10.1016 /$ j.comcom.2018.09.011

Khaledi, M. and A.A. Abouzeid, 2013. Auction-based spectrum sharing in cognitive radio networks with heterogeneous channels. Proceedings of the Information Theory and Applications Workshop, Feb. 10-15, IEEE Xplore Press, San Diego, CA, USA. DOI: 10.1109/ITA.2013.6502923

Krishna, V., 2002. Auction Theory. 1st Edn., Academic Press, ISBN-10: 012426297X, pp: 303.

Liu, Z and C. Li, 2017. On spectrum allocation in cognitive radio networks: a double auction-based methodology. Wireless Netw., 23: 453-466.

Lu, L., X. Zhou, U. Onunkwo and G.Y. Li, 2012. Ten years of research in spectrum sensing and sharing in cognitive radio. EURASIP J. Wireless Commun. Network., 18: 2-16.

Marinho, J. and E. Monteiro, 2012. Cognitive radio survey on communication protocols, spectrum decision issues and future research directions. Wireless Netw., 18: 147-164. DOI: $10.1007 / \mathrm{s} 11276-011-0392-1$

McAfee, R.P., 1992. A dominant strategy double auction. J. Economic Theory, 56: 434-450. DOI: 10.1016/0022-0531(92)90091-U

McHenry, M.C., P.A. Tenhula, D. McCloskey, D.A. Roberson and C.S. Hood, 2006. Chicago spectrum occupancy measurements and analysis and a longterm studies proposal. Proceedings of the International Workshop on Technology and Policy for Accessing Spectrum, (PAS' 06), ACM. DOI: $10.1145 / 1234388.1234389$

Mitola III, J. and G. Maguire Jr, 1999. Cognitive radio: Making software radios more personal. Personal Commun., 6: 13-18.

Nguyen, Q.B.V., Q.C. Le, Q.P. Le, D.T. Tran and T.Q. Nguyen et al., 2011. Vietnam spectrum occupancy measurements and analysis for cognitive radio applications. Proceedings of International Conference on Advanced Technologies for Communications, Aug. 2-4, IEEE Xplore Press, Da Nang, Vietnam, pp: 135-143. DOI: 10.1109/ATC.2011.6027452

Pandit, S. and G. Singh, 2015. An overview of spectrum sharing techniques in cognitive radio communication system. Wireless Netw., 23: 497-518. DOI: $10.1007 / \mathrm{s} 11276-015-1171-1$ 
Parsons, S., J.A. Rodriguez-Aguilar and M. Klein, 2011. Auctions and bidding: A guide for computer scientists. ACM Comput. Surveys, 43: 1-66. DOI: $10.1145 / 1883612.1883617$

Sengupta, S. and M. Chatterjee, 2008. Designing auction mechanisms for dynamic spectrum access. Mobile Netw. Applic., 13: 498-515.

Su, J., J. Wang and W. Wu, 2011. A truthful bilateral multiunit auction for heterogeneous cognitive radio networks. Int. J. Distributed Sensor Netw. DOI: 10.1155/2011/350476

Sun, Y.E., H. Huang, M. Tian, Z. Sun and W. Yang et al., 2015. STRUCTURE: A strategy proof double auction for heterogeneous secondary spectrum markets. Proceedings of the International Conference on Algorithms and Architectures for Parallel Processing, (APP' 15), Springer, Chine. DOI: 10. 1007/978-3-319-27140-8 30

Teng, Y., Y. Zhang, C. Dai, F. Yang and M. Song, 2011. Dynamic spectrum sharing through double auction mechanism in cognitive radio networks. Proceedings of the IEEE Wireless Communications and Networking Conference, Mar. 28-31, IEEE Xplore Press, Cancun, Quintana Roo, Mexico. DOI: 10.1109/WCNC.2011.5779112

Tragos, E.Z., S. Zeadally, A.G. Fragkiadakis and V.A. Siris, 2013. Spectrum assignment in cognitive radio networks: A comprehensive survey. IEEE Commun. Surveys Tutorials.

DOI: 10.1109/SURV.2012.121112.00047

Wang, J., M. Ghosh and K.S. Challapali, 2011a. Emerging cognitive radio applications: A survey. IEEE Commun. Magazine. DOI: 10.1109/MCOM.2011.5723803

Wang, W., B. Li and B. Liang, 2011b. District: Embracing local markets in truthful spectrum double auctions. Proceedings of the 8th Annual IEEE Communications Society Conference on Sensor, Mesh and Ad Hoc Communications and Networks, Jun. 27-30, IEEE Xplore Press, Salt Lake City, UT, USA. DOI: 10. 1109/SAHCN.2011.5984938

Wang, X., Z. Li, P. Xu, Y. Xu and X. Gao et al., 2010a. Spectrum sharing in cognitive radio networks-an auction based approach. IEEE Trans. Syst. Man Cybernet., 40: 587-596.

DOI: $10.1109 /$ TSMCB.2009.2034630

Wang, B. and K.J.R. Liu, 2011. Advances in cognitive radio networks: A survey. IEEE J. Selected Top. Signal Process., 5: 5-23.

Wang, Q., B. Ye, T. Xu, S. Lu and S. Guo, 2012. DOTA: A double truthful auction for spectrum allocation in dynamic spectrum access. Proceedings of the IEEE Wireless Communications and Networking Conference, Apr. 1-4, IEEE Xplore Press, China, pp: 1490-1495.

DOI: 10.1109/WCNC.2012.6214017
Wang, S., P. Xu, X. Xu, S. Tang and X. Li et al., 2010 b. TODA: Truthful online double auction for spectrum allocation in wireless networks. Proceedings of the IEEE Symposium on New Frontiers in Dynamic Spectrum, Apr. 6-9, IEEE Xplore Press, Singapore. DOI: $10.1109 /$ DYSPAN.2010.5457905

Wu, F. and N. Vaidya, 2011. SMALL: A strategy-proof mechanism for radio spectrum allocation. Proceedings of the IEEE INFOCOM, Apr. 10-15, IEEE Xplore Press, China, pp: 81-85.

DOI: $10.1109 /$ INFCOM.2011.5935304

Xing, X., T. Jing, W. Cheng, Y. Huo and X. Cheng, 2013. Spectrum prediction in cognitive radio networks. IEEE Wireless Commun., 20: 90-96. DOI: 10.1109/MWC.2013.6507399

Xue, J., Z. Feng and P. Zhang, 2013. Spectrum occupancy measurements and analysis in Beijing. IERI Proc., 4: 295-302. DOI: $10.1016 /$ j.ieri.2013.11.042

$\mathrm{Xu}$, T., Z. Li, J. Ge and H. Ding, 2014. A survey on spectrum sharing in cognitive radio networks. KSII Trans. Internet Inform. Syst., 8: 3751-3774.

Zhai, X., T. Zhou, C. Zhu, B. Chen and W. Fang et al., 2018. Truthful double auction for joint internet of energy and profit optimization in cognitive radio networks. IEEE Access, 6: 23180-23190. DOI: 10.1109/ACCESS.2018.2817516

Zhang, X., D. Yang, G. Xue, R. Yu and J. Tang, 2018. Transmitting and sharing: A truthful double auction for cognitive radio networks. Proceedings of the IEEE International Conference on Communications, May 20-24, IEEE Xplore Press, USA.

DOI: 10.1109/ICC.2018.8422505

Zhao, Q. and B.M. Sadler, 2007. A survey of dynamic spectrum access. IEEE Signal Process. Magazine, 24: 79-89. DOI: 10.1109/MSP.2007.361604

Zhou, X. and H. Zheng, 2009. TRUST: A general framework for truthful double spectrum auctions. Proceedings of the IEEE INFOCOM, Apr. 19-25, IEEE Xplore Press, Brazil, pp: 999-1007. DOI: 10.1109/INFCOM.2009.5062011 